\title{
PERAN RI DALAM MENYIKAPI VANUATU PADA GERAKAN SEPARTISME PAPUA
}

\author{
RI'S ROLE IN RESPONDING TO VANUATU TO THE PAPUA SEPARTISM MOVEMENT
}

\author{
Siti komariah \\ Program Studi Hubungan Internasional, Fakultas Ilmu Sosial Dan Ilmu Politik, \\ Universitas SingaPerbangsa Karawang \\ E-mail : 2010631260010@student.unsika.ac.id
}

\begin{abstract}
ABSTRAK
Indonesia merupakan negara yang memiliki kedaulatan bangsa serta tanggung jawab atas segala ancaman yang merusak tatanan kehidupan NKRI. Indonesia memiliki negaranegara kawasan timur yang memiliki kesamaan ras dan budaya melanesia yaitu di provinsi maluku utara, nusa tenggara, maluku, papua barat dan papua. Bagi negara kecil pasifik luasnya wilayah Indonesia membawa potensi dari berbagai masalah keamanan. Terutama dalam aksi propaganda separatisme papua yang sangat meresahkan tatanan NKRI yang menyebabkan konflik dalam negeri. Sebagai negara pasifik dan memiliki kesamaan etnis Melanesia seperti Vanuatu bersih keras mendukung secara moral dalam diplomatik untuk kemerdekaan papua.
\end{abstract}

Kata kunci : Separatisme papua, diplomatik, Vanuatu, Indonesia, keamanan dan keadilan

\begin{abstract}
Indonesia is a country that has national sovereignty and is responsible for all threats that damage the order of life of the Republic of Indonesia. Indonesia has eastern countries that share the same race and culture as Melanesian, namely in the provinces of North Maluku, Nusa Tenggara, Maluku, West Papua and Papua. For a small Pacific country, the vast territory of Indonesia brings the potential for various security problems. especially in the propaganda action of Papuan separatism which deeply disturbed the structure of the Unitary State of the Republic of Indonesia which caused domestic conflict. as a pacific country and have Melanesian ethnic similarities such as Vanuatu, it is hard to morally support diplomatic efforts for Papuan independenc.
\end{abstract}

Keywords : Papuan separatism, diplomatic, Vanuatu, Indonesia, security and justice

\section{PENDAHULUAN}

Terletak di barat daya samudra pasifik yaitu negara Vanuatu yang berdekatan dengan Negara Australia Republik vanuatu ini terdiri atas 13 pulau serta 60 pulau kecil yang berbentuk huruf "Y" ibu kotanya Negara Vanuatu ini adalah port-vila yang terletak di kepulauan Efate pulau tersebut merupakan pulau ternama di Negara Vanuatu. 
Melanesian dengan mayoritas dan polenesia sebagaimana minoritasnya. Bahasa yang di gunakan dari Negara Vanuatu yaitu berbahasa prancis,inggris dan bislama. Vanuatu ini di pimpin oleh kepala Negara presiden (Tallis Obed Mones). Masyarakat Vanuatu Setiap tanggal 30 juli tidak pernah terlewatkan dengan perayaan kemerdekaan negaranya atas kependudukkan prancis dan inggris. Negara ini mempunyai sejarah yang berada di kepulauan pasifik selatan dalam sejarah tersebut sangat melekat dengan penjajahan bangsa eropa dulu. Negara ini sering sekali menyoroti dugaan HAM serta mendukung separatisme papua merdeka supaya lepas dari wilayah genggaman kesatuan Indonesia . Meskipun kerap kali di remehkan sebagai Negara kecil Vanuatu sangat berani dalam mengusik kedaulatan dan keutuhan di wilayah Indonesia mereka terus menyatakan dukungan terhadap kemerdekaan papua barat. Tak henti hentinya mencari permasalahan dengan Indonesia mereka terus mengusik seolah-olah Indonesia mempunyai kesalahan yang sangat besar. Perdana menteri Negara Vanuatu memegang perananan penting dalam Melanesian Spearhead Group (MSG), Vanuatu ini menjadi salah satu organisasi regional utama di wilayah kawasan pasifik selatan, tidak hanya vanuatu saja yang menjadi kawasan regional akan tetapi ada beberapa negara juga yang ikut serta bergabung dalam organisasi $M S G$ diantarannya yaitu Negara timor leste,Vanuatu, papua nugini, kaledonia baru, kepulauan salomon, dan Fiji.

Organisasi Papua Merdeka atau di sebut dengan (OPM) merupakan sebuah organisasi yang berdiri pada tahun 1965 Opm ini ingin keluar dan memisahkan diri dari pemerintahan wilayah Indonesia. Awal mulannya di kenal dengan provinsi irian barat sejak tahun 1969-1973 dan masa itu di ganti lagi menjadi provinsi irian jaya oleh Soehato pada masa peresmian tambang tembaga dan juga emas. Dan ada perubahan lagi menjadi provinsi papua sesuai dengan UU No 21/2001. masyarakat papua sangat angkuh mereka ingin memisahkan diri dari negara Indonesia karena mempunyai motif umum dan merasa kecewan terhadap situasi yang tidak adil yang di berikan Indonesia terhadap wilayah papua ini. Papua atau sering kali di sebut oleh masyarakat internasional sebagai west papua bagian dari wilayah teritori pemerintahan Indonesia yang sedang mengalami konflik separatisme. Pemerintah Indonesia telah membagi kawasan wilayah papua menjadi dua bagian region antara lain yaitu papua dan papua barat. Meski sudah menjadi bagian dari pemerintahan Negara Republik Indonesia yang telah di sepakati melalui Act of free choice pada tahun 1969, akan tetapi banyak sekali masyarakat papua yang merasa mereka bukan menjadi bagian dari wilayah Indonesia mereka menginginkan kemerdekaan bagi wilayah papua barat. selain itu adannya 
dukungan kuat dari Negara Vanuatu untuk wilayah papua yang menyebabkan konflik separatisme antara indonesia dan papua, masalah ini cukup terbilang sangatlah rumit dan menimbulkan konflik sampai sekarang. Akibat dari konflik itu munculah perlawanan yang di wakilkan oleh para diplomat muda asal indonesia yang berjuang dan membantah tudingan dari Vanuatu seolah Negara Indonesia tidak peduli terhadap wilayah papua dan banyak tudingan lain yang di lontarkan oleh Negara Vanuatu terhadap Indonesia pada sidang Majelis Umum PBB.

\subsection{Rumusan Masalah}

Terjadinya aktor-faktor yang menyebabkan pelanggaran HAM di papua barat yang di lakukan oleh aparat keamanan Negara papua justru akhir-akhir ini mulai meningkat dan merajarela. Akar masalahnya yaitu adannya peminggiran serta diskriminasi yang di sebabkan minimnya pengakuan atas konstribusi papua bagi Indonesia. munculnya ketidak optimalan pembangunan atas insfraksruktur sosial di papua. ketidak jaminan kesehatan dan pendidikan yang di alami masyarakat papua serta Proses integrasi politik dan sosial budaya yang belum tuntas. Pelanggaran HAM yang belum juga di selesaikan yaitu khususnnya warior, wamena dan paniai. Itu sudah sangat menjadi ancaman bagi keamanan Indonesia dan sekitarnya mereka dengan nafsu membuat keributan serta konflik memanas yang merugikan sekitar. Dan tak sedikit orang menjadi korban dalam konflik ini. Aksi bersenjata internasional gerakan separatisme papua merupakan sekelompok realitas mempunyai kekuasaan yang jalankan oleh masyarakat papua mereka belum juga dapat menerima hasil dari pepera tahun 1969 yang sudah di nilai secara rekayasa oleh pemerintahan pada zaman soeharto untuk kepentingan integrasi politik internasional waktu itu. Kampannnye internasional yang di lakukan separatisme papua dalam arena diplomasi awalnya dari keterbatasan gerakan separatis dalam melakukan perlawanan secara fisik melalui aksi militer yang telah mencantumkan bahwa diplomasi sebagaimana kelanjutan perang dalam bentuk yang berbeda dari perang pada umumnya.

Maraknya separatisme dalam politik internasional membuat semakin banyak yang ikut serta dalam kampanye internasional dalam arena diplomasi internasional, hal ini menyebabkan kondisi wilayah bagian timur di Indonesia dari semula terisolasi dalam isu lokal dan sekarang malah menjadi perhatian komunitas internasional. papua serta Vanuatu memang sedang menjadi perbincangan hangat di masa sekarang karena Vanuatu merupakan Negara yang begitu kuat mendukung adannya separatisme di wilayah papua ini 
menjadi buah kebijakan bagi sekuritisasi papua serta Vanuatu melalui pendekatan keamanan. Upaya kampanye internasional dalam jalur diplomasi di papua mulai di perluas dengan adannya pemanfaatan jalur diplomasi parlemen. Salah satu tokohnya yaitu bernama beny wenda, yang pernah di tangkap oleh aparat keamanan Indonesia karena dia melarikan diri ke Negara inggris. Wenda merupakan aktivis dari mejelis suku papua barat dia telah berhasil dalam westmenster untuk meluncurkan internasional parliamentarians for west papua sehingga papua barat sudah membentuk parlemen inggris, wenda juga sudah mendirikan kantor perwakilan organisasi papua merdeka atau di sebut dengan OPM.

\section{TINJAUAN LITERATUR}

\subsection{Konflik Yang Terjadi Di Wilayah Papua}

Berbagai ancaman yang datang ke Negara kita Indonesia, separatisme merupakan salah satu ancanaman yang paling utama bagi Negara Indonesia karena itu termasuk ancamanan dari dalama Negara bukan dari luar dan itu juga menyangkut atas masalah kedaulatan Negara Indonesia. Pemisahan dari wilayah Indonesia, mendirikan pemerintahan otonom, memikirkan nasib tersendiri itu sudah termasuk dalam gerakan separatisme ( McHenry,2009 ). Gerakan separatisme yang bergerak untuk memisahkan diri dari Negara Indonesia, penyebabnya pun banyak termasuk dari kekecewaan masyarakat papua terhadap penegakkan dari pemerintahan Indonesia yang merasa tidak adil dalam menjalankan tugas. Permasalahan tersebut terindektifikasi dari laporan kunjungan komisi 1 DPR RI pada tahun 2012 di papua, di antaranya yaitu : 1. Tingkat kepercayaan dari masyarakat papua terhadap Indonesia yang sangat minim dan jika di bilang sudah tidak adannya kepercayaan terhadap pemerintahan Indonesia; 2. Isu yang sangat kuat dari isu politik dalam progress intergrasi papua; 3. Adannya perlambatan dari ketidak efektipan pembangunan antara papua dan papua barat; 4. Kurangnya kinerja pada pilkada dan lemahnya kinerja pemerintahan kota atau kabupaten; 5. Menyebarluasnya aksi dari kekerasan bersenjata yang kejam di wilayah papua ( Papua Review, 2012 ). Walter Hadye lini (1980-1991) dia adalah menteri pertama di Negara Vanuatu berkomunikasi langsung atas dasar kemerdekaan di Vanuatu itupun belumlah sepenuhnya merdeka dengan cukup sempurna karena seluruh bangsa dari wilayah Melanesia belum juga terbebas dari kolonialisme, inilah asal-mualasal serta alasan kenapa Vanuatu sangat bersi keras mendukung kebebasan dan kemerdekaan untuk papua barat. Konflik hal yang ingin kita 
hindari mengingat hubungan antara manusia dan sosial merupakan suatu hal yang statis ( Francis, 2002 ) konflik yang terjadi pada separatisme papua memiliki latar belakang sangatlah kuat dan rumit apalagi di sertai dengan adannya dukungan dari Negara Vanuatu. Pada awal kemerdekaan tahun 1945 mulai adannya perebutan wilayah papua yang melibatkan pemerintahan Indonesia pada kala itu baru merdeka. ( Chauvel \& Bhakti, 2004). Dari situ lah mulai adanya permasalahan dari pemerintah Indonesia yang ingin memiliki wilayah papua menjadi bagian dari wilayah Indonesia supaya menjadi Negara kesatuan. Pemerintah belanda pada saat itu merasa masih memiliki kekuasaan atas dasar teritori dan menganggap bahwa wilayah papua yang dulu nya memiliki wilayah kesatuan politik yang berbedan dengan Indonesia, dalam sejarah di tentukan langsung oleh ratu belanda pada tahun 1949 ( Sugandi, 2008). perbedaan kasus papua ini kemudian di ambil alih oleh perwakilan Indonesia ke ranah internasional dalam perundingan perserikatan bangsa-bangsa atau di sebut dengan PBB.

Adannya pemahaman atas konstribusi terhadap transformasi konflik dan munculnya isu pada pasca perang dingin. Konflik pada era baru ini di warnai dengan perjuangan terhadap hak-hak individu serta hak asasi manusia serta di dominasi oleh masyarakat sipil tanpa adannya kekerasan sepihak atau kelompok untuk melindungi dasar individu. Ada beberapa pegaruh terhadap transformasi konflik yang tidak terpenuhinya kebutuhan hal inilah muncul dengan adannya permasalahan serta konflik yang tak kunjung usai ( francis,2002). dari kasus separatisme yang terjadi di papua barat merupakan tindakan yang mendasarkan keinginan untuk merdeka yang di perankan oleh sebuah Negara ataupun masyarakat yang bersangkutan ( Fearon,2004 ). Menurut fearon sendiri separatisme yang terjadi di papua barat tindakan dan perbuatannya sangat "membangkang" dari sebuah bangsa dan wilayah yang menginginkan kebebasan merdeka. Separatisme adalah juga sebuah konsekuensi yang muncul atas diskriminasi terhadap sistem ekonomi dan politik.

\subsection{Sikap Indonesia Terhadap Negara Vanuatu}

Indonesia Negara berdaulat tempat terjadinya ancaman separatisme dalam gerakan kemerdekaan papua barat itu tentunya banyak sekali dukungan dari Negara pasifik selatan terutama Negara Melanesia vanuatu. Respon dan tanggapan yang di berikan Indonesia kepada Vanuatu dalam bentuk bilateral memberikan berbagai macam bantuan seperti di bidang teknologi,pendidikan dan sebagainnya( Sabir,2018,p.97 ). Apabila masuk ke konteks bilateral itu akan menjadi respon keras bagi negara indonesia untuk vanuatu dari 
berbagai ancaman yang datang terhadap kerasnya dukungan Negara Vanuatu atas kemerdekaan di papua barat dalam ancaman diplomatik, kritik dalam hak asasi manusia. Dari pihak Indonesia juga menegaskan bahwa jangan ada lagi yang melakukan intervensi urusan tentang domestic di Indonesia. Dalam konteks umum PBB ke 73 yang di sampaikan oleh wakil presiden jusuf kalla pada sesi debat dan membuahkan kritikkan dari perwakilan Negara Vanuatu yaitu benny wenda kedalam sidang. Sehingga di balas kecaman balik oleh jusuf kalla yang di wakilkan oleh individu Indonesia pada forum berikut : "Indonesia tidak akan tinggal diam apabila Negara Vanuatu terus mengusik kedaulatan teritori Indonesia terus menerus". Dalam hal ini, sangat buruk jika menjadi bagian dari separatisme papua. "tindakan ini tidak aka nada tempat bagi system PBB. Ini hanyalah menjadi suatu tindakan melanggar prisip PBB saja ( Sihombing,2018).

Maksimalnya Indonesia melihat vanuatu mendukung separatisme papua hanya membuat kecaman semata dan kritikan yang tidak melakukan cara kekerasan sedikitpun. Melainkan dengan respon dalam sikap diplomatis, serta berpikir diplomatis. ketegangan pun mulai muncul menyelundupkan benny wenda pada sidang PBB waktu itu. Termasuk dalam dukungan Vanuatu terhadap papua barat, melalui hal ini kementerian luar negeri Indonesia yang di pimpin oleh menteri Retno marsudi dia merespon sikap Vanuatu dengan pikiran diplomatis. " menegaskan bahwa bangsa Indonesia tidak akan pernah mundur apabila ini sudah menyangkut sovereugnity ata kedaulatan Negara Indonesia dan integritas wilayah Indonesia ( medcom,2018 ). Retno marsudi berkomitmen untuk menjaga kedaulatan bangsa Indonesia meskipun Indonesia tidak menggunakan soft power seperti diplomasi publik,kritik,dan yang lainnya. Yang mana soft power ini di anggap sebagai sebuah langkah yang menuju efektid dari pada melakukan hard power ( Omega,2017 ). Dukungan propaganda yang di berikan Vanuatu terhadap papua masuk kedalam konstitusi yang di sebut bahwa Negara Vanuatu menginginkan kebebasan bangsa Melanesia, termasuk papua barat yang pernah di jajah oleh bangsa asing ( Sudrajat,2017). Vanuatu sangat berani mengusik tatanan Negara di wilayah Indonesia dan Negara Vanuatu ini pro dalam separatisme papua barat yang ingin memisahkan diri dari wilayah Indonesia. Vanuatu ini menyatakan misinya dalam memboikot "Melanesia spearheas group" ( MSG) pada tanggal 16 januari 2014 Melalui Edward Natapei dia seorang perdana menteri luar negeri yang menyatakan bahwa dia akan bersedia menjadi delegasi MSG apabila mendapat kesempatan untuk bertemu langsung dengan kelompok lokal, kelompok pro kemerdekaan 
serta kelompok yang lainnya yang mempunyai perhatian besar terhadap masalah konflik yang terjadi di papua barat (News ABC,2014).

Untuk dapat mencapai melanesia renaissance maka di adakan permainan dalam posisi penting di pacific island group dalam membantu Negara kepulauan kecil atas permasalahan pembangunan dalam meningkatkan transformasi (Cain, 2015 ). Ada pernyataan resmi yang di sampaikan oleh menteri Vanuatu moana kalosil dalam pidatonya dia menyampaikan kondisi yang memprihatinkan di papua barat. Moana menyampaikan tanggapan tersebut kepada presiden konferensi di janewa bahwa dia sangat focus dalam perilaku suara masyarakat papua yang kurang perhatian dan sering di abaikan di mata internasional. moana koasil menginginkan akses kepada para ahli hak asasi manusia dan wartawan internasional serta lembaga internasional untuk mengunjugi dan melihat kondisi papua sekarang ( free west papua, 2014 ). Keberanian dari Negara Vanuatu dalam mendukung gerakan separatisme papua barat ini menarik perhatian bahwa Vanuatu ingin melihat papua barat memisahkan diri dari inidonesia. Kepentingan Vanuatu dalam mendukung papua karena di pengaruhi oleh dua variabel yaitu domestic politik serta nilai lokalnya. Dukungan atas kemerdekaan papua oleh Negara Vanuatu merupakan hal dari bentuk domestic politik Vanuatu yang mempunyai orientasi dalam kebijakan luar negeri hal ini menjadi salah satu kekuatan bagi pentingnya melakukan Melanesia Renaissance ( Putnam, 434 ). Melanesia Renaissance mengangkat isu dalam memfokuskan utama Vanuatu dalam upaya kemerdekaan terhadap wilayah Melanesia yang belum juga memenangkan kemerdekaan. Pihak tergugat yaitu Indonesia oleh Vanuatu agar isu ini mendapatkan respon untuk kemerdekaan papua barat. Domestic politik Negara Vanuatu dalam menghubungkan sosialisme Melanesia mempunyai prinsip saling berbagi dan peduli dalam pengambilan keputusan, sosialisme Melanesia memerlukan perubahan sosial,politik, ekonomi secara radikal, dan kemudian mempunyai wewenang tugas untuk memberikan revolusioner secara tepat ( premdas,1987 ). Indonesia cenderung menyadari atas perilaku Vanuatu yang mendukung separatisme di papua barat. Namun, baru-baru ini Indonesia menanggapinya sebagai ancaman serius, semakin tinggi vocal dari Negara Vanuatu di berbagai forum internasional pada isu separatisme. Indonesia lantas melakukan pendekatan terhadap Negara Vanuatu melalui pemanfaattan instrumen kerja sama dalam bidang ekonomi, beasiswa,pembangunan, peternakan dan lain-lain ( buku diplomasi, 2014 ). Akan tetapi, upaya diplomasi yang di lakukan terhadap Negara Vanuatu tampaknya tidak membuahkan respon positif dia tetap mendukung penuh atas wilayah papua barat. Vanuatu 
dan sejumlah Negara pasifik selatan secara terang-terangan menyatakan dukungan yang kuat atas kemerdekaan papua barat dengan meminta PBB melakukan investigasi dalam menyerukan agar papua barat di berikan kebebasan dan hak nasib sendiri dalam sidang tahunan majelis umum PBB ke-71 di new York, amerika serikat ( Rappler,2017 ). Dalam menyikapi dugaan Vanuatu serta Negara pasifik lainnya mendukung papua barat aliansi mahasiswa papua atau di sebut dengan APM melakukan aksi demonstrasi dalam kasus sidang PBB. Ucapan yang di sampaikan APM dia berterimakasih atas dukungan Vanuatu dan Negara pasifik lainnya terhadap wilayah papua atas dukungan diplomatik terhadap perjuangan kemerdekaan papua barat ( Suara papua, 2014 ). Hal ini sangat terlihat jelas bahwa sekelompok pro separatis di dalam negeri mendukung aksi Negara Vanuatu terhadap Indonesia. Usik RI soal papua sebagaimana Vanuatu negeri dengan julukkan seujung kuku ini menyinggung soal papua barat merdeka pada sidang majelis umum perserikatan bangsa-bangsa ( PBB ).

\section{METODOLOGI PENELITIAN}

Dalam hal ini peneliti menggunakan metode yang kuantitatif, sumbernya pun terdiri dari sumber data sekunder dalam bentuk deskripsi sebuah isu yang di peroleh dari berbagai sumber jurnal yang baik dan di media massa internasional yang terlibat atas isu yang penulis gunakan untuk membuat penulisan secara baik dan benar dalam meneliti sebuah isu yang terjadi di Indonesia dalam separatisme papua dengan dukungan negara Vanuatu. Teknik dalam pengumpulan data-data terkait isu yang bersangkutan di lakukan dalam mencari studi pustaka. Studi pustaka dapat di artikan sebagai suatu langkah dalam memperoleh informasi penelitian terlebih dahulu menggunakan data sekunder yang terdapat dari public

\section{HASIL DAN PEMBAHASAN}

Melanesian Spearhead Group ( MSG ) berawal dari adannya organisasi yang berdiri di port Vila pada 14 maret 1968 serta beralihlah menjadi organisasi resmi regional yang telah mewakili seluruh keturunan dari Melanesia yang telah di akui oleh PBB pada tahun 2007 di mana beranggotakan Negara Fiji, papua nugini,papua, kepulauan salomon, dan Vanuatu yang di sebut dengan Negara yang pro dengan kemerdekaan. sebagai organisasi 
regional di wilayah pasifik selatan yang identik dengan ras Melanesia dalam prot villa Vanuatu. Letak dalam kedekatan geografis dalam persamaan ras tersebut muncullah keberanian Vanuatu untuk ikut terlibat dalam separatisme papua serta memboikot Melanesian Sprearhed Group ( MSG ) ke Negara Indonesia pada bulan januari 2014. Dengan perdana menteri luar negeri Edwar Natapei dia menyatakan kesediaan dalam menjadi utusan untuk organisasi MSG dalam pro kemerdekaan.

Usaha yang di lakukan oleh Negara Vanuatu mendapat dukungan penuh kepada papua untuk memisahkan diri dari Indonesia dan mendapatkan kemerdekaan dengan mempunyai kepentingan khusus Vanuatu yaitu : Pertama, Vanuatu memberikan dukungan kepada kemerdekaan papua dalam bentuk etnik Melanesia. Dekatnya etnis membuat Vanuatu dan papua menimbulkan rasa kesal dan emosional yang meninggi dari keduannya terhadap Indonesia, terutama pada kekerasan hak asasi manusia yang di alami oleh masyarakat papua pada masa itu. Kedua, menginginkan Negara Vanuatu menjadi pemimpin regional dalam upaya mendukung ras Melanesia di kemerdekaan papua. Keinginan yang kuat untuk menjadi pemimpin kawasan region merupakan eksistensi politik Vanuatu dalam menegakkan Melanesia Renaissance. Melanesia Renaissance merupakan keinginan mimpi yang di gapai dan aspirasi para pendiri Melanesian spearhead Group. Walker lini dia adalah seorangg advokat dari Melanesia yang menyuarakan kemerdekaan atas papua serta kepulauan salomon pada awal 1980 untuk bisa bekerja sama pada umumnya, serta prinsip dalam ekspetasi untuk memperjuangkan identitas kemerdekaan papua ( PacNews,2013 ). Dalam tantangan keamanan Nasional untuk Indonesia dapat di definisikan sebagaimana kemampuan Negara untuk bisa menjaga ancaman yang datang dari luar, cohen dan tuttle herman (1977) berpendapat bahwa dalam keamanan ini dapat di artikan sebagai kondisi yang protektif sebagaimana pemerintah dalam aparatur Negara menjaga ancaman internal dan eksternal (Herman, 1997).

\section{KESIMPULAN}

Negara yang terletak di barat daya samudra pasifik yaitu Negara Vanuatu yang terdiri dari 13 pulau serta 60 pulau kecil nama ibukotannya yaitu port-vila terletak di efate. Adannya dukungan kuat dari Negara Vanuatu untuk papua barat yang menimbulkan konflik separatisme anatara Indonesia dan papua. terjadinya aktor-aktor yang menyebabkan 
pelanggaran ham di papua barat yang di lakukan oleh aparat papua. Proses integrasi politik dan sosial yang belum juga tuntas. Maraknnya separatisme dalam politik internasional dalam arena diplomasi internasional yang menyebabkan kondisi wilayah bagian timur di Indonesia yang semula terisolasi menjadi perhatian komunitas internasional. ada salah satu tokoh yang tersorot yaitu beny wenda dia pernah di tangkap oleh aparat keamanan Indonesia karena dia berusaha melarikan ke Negara inggris.

\section{DAFTAR PUSTAKA}

\section{JURNAL :}

[1] Adriana Elisabeth. 2006. Dimensi Internasional Kasus Papua. Jurnal Penelitian Politik, Vol.3,No.1

[2] Ahmad Sabir. 2018. Diplomasi Publik Indonesia terhadap Vanuatu Dalam Upaya Membendung Gerakan Separatisme Papua. Jurnal Hubungan Internasional, Tahun XI,No.1

[3] Wardhani, Baiq L. S. W. "Quo Vadis Melanesian Spearhead Group.” Jurnal Global dan Strategis, Vol.9,No.2 (juli 2015):190-206.

[4] Putnam, Robert D. Diplomacy and domestic politics: the logic of two-level games. Internasional Organization: Vol 42,No.3. Summer 1988.

[5] Komisi Hak Asasi Manusia. Jakarta, Jurnal Komnas Ham, 2015 XXVII + 173 Halaman. Vol.12. Tahun 2016g

\section{SUMBER ONLINE :}

[6] Vanuatu persoalkan sidang umum di PBB (1 November,2021). di unduh dari : https://jurnalgarut.pikiran-rakyat.com/nasional/pr-332680889/lagi-vanuatupersoalkan-ham-di-papua-lewat-sidang-pbb

[7] sejarah kemerdekaan papua Oleh: Wisnu Amri Hidayat, Iswara N Raditya (30 Juli, 2019) "Sejarah Kemerdekaan Vanuatu \& Dukungan Papua Merdeka", di unduh dari : https://tirto.id/sejarah-kemersekaan-vanuatu-dukungan-papua-merdeka-efhx 